\title{
In Vitro Micropropagation of Jatropha curcas L. from Bud Aggregates
}

\author{
Samson Daudet Medza Mve ${ }^{1, *}$, Guy Mergeai ${ }^{1}$, Philippe Druart ${ }^{2}$, Jean Pierre Baudoin ${ }^{1}$ and \\ André Toussaint ${ }^{1}$
}

${ }^{1}$ Université de Liège-Gembloux Agro-Bio Tech, Unité de Phytotechnie tropicale et Horticulture. Passage des Déportés, 2 BE-5030 Gembloux, Belgium

${ }^{2}$ Centre de Recherche Agronomique Wallon, Département Sciences du vivant Unité Génie biologique chaussée de Charleroi, 234 BE-5030 Gembloux, Belgium

\begin{abstract}
Entire plants were regenerated from nodes explants of Jatropha curcas L. following a procedure of bud

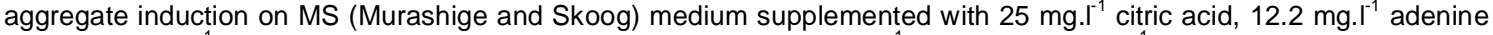

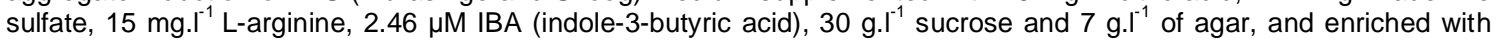
different balances of BA (benzyladenine) and L-glutamine. The histological studies performed on aggregates showed that the buds result from both the development of axillary buds and adventitious budding starting from underlying tissues of the explant. The culture medium containing $6.65 \mu \mathrm{M} \mathrm{BA}$ and $25 \mathrm{mg.I}^{-1}$ L-glutamine gave the best results with an average of 64 buds per aggregate after three weeks for all accessions tested. The buds developed into shoots when placed in an MS medium supplemented with $2.21 \mu \mathrm{M}$ BA, $5.70 \mu \mathrm{M}$ IAA (indole-3-acetic acid) and $15 \mathrm{mg}^{-1} \mathrm{~L}^{-}$-arginine. These shoots were isolated and then rooted in MS containing $2.46 \mu \mathrm{M}$ of IBA, $2 \%$ sucrose and $0.7 \%$ agar. The entire process took 13 weeks with a $98 \%$ survival rate in terms of plantlets acclimatization. We obtained a multiplication rate of 13 buds per explant and per subculture which is the double of those obtained in other recent works based on the micropropagation of $J$. curcas from node explants. This protocol is economically more profitable.
\end{abstract}

Keywords: Jatropha curcas L., bud aggregates, nodal explant, regeneration, in vitro culture.

\section{INTRODUCTION}

Among the plant species producing raw materials for biofuels, Jatropha curcas L. is one of the plant species that stimulates the highest interest in tropical and subtropical regions. The seeds contain up to $38 \%$ in non-edible oil which is highly combustible [1]. The use of $J$. curcas for the production of biofuel could compensate for energy shortages, reduce $\mathrm{CO}_{2}$ gas (Carbon dioxide) emissions and contribute to increase farmers' revenues [2]. However, several challenges remain before that plant biomass can be commercially exploited. Its supply on a large scale requires massive production of phenotypically homogeneous plantmaterial of a very high quality within a short time-frame that is adapted to the growth conditions of the plantation areas. Multiplication of the plant is traditionally carried out by sowing seeds or planting cuttings directly in the field or after a first period of growth in nurseries. But sowing has the disadvantage of producing heterogeneous plants with regard to their production capacity [3]. The plants produced from cuttings develop a superficial rooting system which renders them sensitive to lodging and constitutes a major obstacle to their establishment in poor and marginal soils [4]. In vitro growth is an

*Address correspondence to this author at the Université de Liège-Gembloux Agro-Bio Tech, Unité de Phytotechnie tropicale et Horticulture. Passage des Déportés, 2. 5030 Gembloux, Belgique; Tél: 003281622683 / 0032812644 ; Fax: 003281622110; E-mail: medzamve@yahoo.fr alternative for massive and rapid production of elite plants. This clonal propagation method has the advantage of producing plants that are morphologically homogenous with an equal production potential. Several authors have regenerated $J$. curcas from nodal explants, from hypocotyls, leaves, petioles and cotyledons [1]. However, the number of plantlets produced per explant remained relatively low after a period of four to six weeks (10 to 42 plantlets per explants) which is not economically viable. The present study aims at optimizing the culture conditions of in vitro micro-propagation from nodal explants with investigations focusing on the most efficient hormonal balance in combination with glutamine and others amino-acids, to induce mass production of bud aggregates.

\section{MATERIAL AND METHODS}

The work was carried out with two types of seeds called "Cam" and "Sen", harvested in 2009 on parental plants aged more than three years and originating from Southern Cameroon (Minkang 1: $2^{\circ} 48^{\prime} 31.28 " \mathrm{~N} ; 12^{\circ}$ 4'41.30"E) and South-East of Senegal (Dialacoto: $13^{\circ} 18^{\prime} 50.04 " \mathrm{~N}$; $\left.13^{\circ} 16^{\prime} 56.82^{\prime \prime O}\right)$ respectively. These seeds were sown in our growth room with a sixteen hours photoperiod, a temperature of $27 \pm 2{ }^{\circ} \mathrm{C}$, a light intensity of $80 \mu \mathrm{mol} \mathrm{m} \mathrm{m}^{-2} \cdot \mathrm{s}^{-1}$ and $50-60 \%$ relative humidity. The nodal explants were picked from at least two months old seedlings which have formed a 
minimum total number of four nodes. They were specifically collected from an area beginning at $10 \mathrm{~cm}$ from the base of the stem and ending at $5 \mathrm{~cm}$ below the apical bud, the latter being discarded at the sampling moment. A petiole piece was kept attached to the stem to prevent putative axillary bud damages due to disinfection. This consisted in washing the explants in a $5 \%$ Dettol solution, dipping them in a $70 \%$ alcohol solution for 20 seconds, and then immersing them in a $10 \%$ calcium hypochlorite solution for thirty minutes under stirring. Finally, the explants were rinsed three times in the laminar flow with sterile distilled water; the second rinse took place under magnetic stirring for 1 minute.

\section{Node Buds Development}

To develop the axillary buds, the sterilized nodes were placed in a growth medium (GM), based on Murashige and Skoog [5] [MS] compounds containing 8.87 $\mu \mathrm{M}$ BA (benzyladenine), $4.92 \mu \mathrm{M}$ IBA (Indole-3-

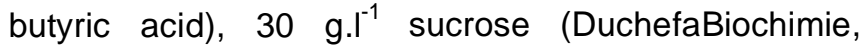
reference 006520.16). The $\mathrm{pH}$ of the GM was adjusted to $5.7 \pm 0.1$ and the medium was solidified with $0.7 \%$ agar (Select Agar Invitrogen, reference 30391-023). The nodal explants were sized to a length of 0.8 to 1 $\mathrm{cm}$, placed on a sterile paper and cultivated for three weeks in $100 \mathrm{ml}$ magenta B-cap containers $(66 \mathrm{~mm} \times$ $59 \mathrm{~mm}$ ); each one containing $20 \mathrm{ml}$ of $\mathrm{GM}$.

\section{Formation and Multiplication of the Bud Aggregates}

The buds developed on GM medium were separated from the stem fragment and transferred to an induction medium (IM) made up of MS enriched with $25 \mathrm{mg} . \mathrm{I}^{-1}$ citric acid, $12.2 \mathrm{mg.} \mathrm{I}^{-1}$ adenine sulfate, $15 \mathrm{mg} . \mathrm{l}^{-}$ ${ }^{1}$ of L-arginine, different concentrations of glutamine $\left(10,15,20,25,30\right.$ and $\left.35 \mathrm{mg} . \mathrm{I}^{-1}\right)$, and five hormonal balances combining $2.46 \mu \mathrm{M}$ IBA and BA (2.21, 4.43, $6.65,8.87$ and $11.1 \mu \mathrm{M}$ ) to bring about the formation of bud aggregates. The tested hormonal balances were chosen on the basis of preliminary investigations [6]. Every three weeks, agregates were fragmented into clusters of 5 to 10 buds which were transferred in a medium of the same composition to proceed with proliferation, or else transferred to an elongation medium with the aim to grow buds into shoots for rooting.

\section{Elongation and Rooting}

The isolated aggregate fragments were first transplanted into an elongation medium (EM), composed of the MS medium supplemented with 2.21 $\mu \mathrm{M} \mathrm{BA}$ and $5.70 \mu \mathrm{M}$ IAA (indole-3-acetic acid), 15 mg. $I^{-1}$ L-arginine, $3 \%$ sucrose and gelled with $0.7 \%$ agar. After 3 weeks of growth, basic hormone free MS medium was added as a second liquid phase to immerse the aggregates base by 1 to $2 \mathrm{~mm}$. The first shoots reaching $\pm 1.5 \mathrm{~cm}$ height, were isolated and transferred one week later for rooting in $1 / 2 \mathrm{MS}$ (containing $2.46 \mu \mathrm{M}$ IBA, $2 \%$ sucrose and $0.7 \%$ agar) while the rest of the aggregate was subcultured in fresh shoot elongation medium. Shoots rooting was started in darkness for the first five days and then root formation was continued under a sixteen-hour photoperiod for three weeks.

\section{Acclimatization}

The residues from the agar medium were removed from the root system by washing it with distilled water. The plantlets were replanted in pots containing commercial compost and placed in the growth chamber where seeds' germination took place. The plantlets were covered with a transparent plastic film for two weeks and progressively adapted to the open air for the next two weeks before their transfer to the greenhouse.

\section{Histological Study}

Histological cuts were carried out on bud aggregates fragments of four weeks old (at least) in accordance with the Ruzin [7] procedure and then stained with toluidine blue.

\section{Parameters Analysed}

The percentage of bud aggregates and the number of newly formed buds/aggregates were recorded at each subculture into IM media. In the elongation medium, the number of shoots per aggregate fragment and their length were noted every four weeks during three successive cycles of micropropagation (42 weeks in total). During the rooting phase, the appearance of roots was observed after 12 days. The number, the length of the roots and the percentage of rooted shoots were recorded after four weeks. Lastly, the survival percentage for plantlets was noted after 5 weeks ex vitro.

\section{Statistical Analysis Method}

The tests were carried out in randomized blocks in order to determine the influence of the accession as well as the induction medium and the glutamine concentration on the number of buds produced and 
rooting. The experimental unit consisted of a fragment of aggregates. In this experimental system, the three factors are the following: induction medium as a fixed qualitative factor (5 items); accession as a fixed qualitative factor (2 items) and glutamine concentration as a fixed quantitative factor ( 6 items).

The statistical analysis used is a fixed crossover model with 60 random simple independent and normal populations with the same variance. Each treatment contained 26 shoots and each treatment was repeated 3 times. Statistically significant differences between means were determined by three-way analysis of variance using Duncan's multiple-range test and the Minitab15 Software and Statistical. A P-value of less than 0.05 was considered significant.

\section{RESULTS}

Each nodal explant from the mother-plants developed one to three axillary buds after three weeks growth in the culture medium (Figure 1a). Both $\mathrm{J}$. curcas accessions showed the same behavior with regard to bud formation in this medium. They were individually replanted in the presence of BA and glutamine to induce bud aggregates (Figure 1b). The average percentage of induced aggregates varied according to the hormonal balance and the concentration of glutamine.

After three weeks, the bud aggregates were fragmented into cluster units of 5 to 10 buds and these were replanted into an $\mathrm{IM}$ medium of the same composition, to form new aggregates. Figures $\mathbf{2 a}$ and $\mathbf{2 b}$ show the average percentage of these units forming new aggregates after five subcultures. The highest regeneration percentage (98\%) was obtained with 6.65 $\mu \mathrm{M}$ BA, $2.46 \mu \mathrm{M}$ IBA, $25 \mathrm{mg} . \mathrm{I}^{-1}$ glutamine and the supplements. The number of buds per unit obtained every three weeks for both accessions (Figures $\mathbf{3 a}$ and 3b) showed highly significant differences according to the hormonal balance and the concentration of glutamine.

The optimal concentrations of BA and glutamine

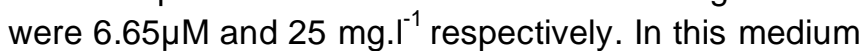
an average of $63.37 \pm 2.90$ buds per aggregate in the Cam accession and $65.13 \pm 1.12$ in the Sen accession were recorded after three weeks. The multiplication rate is the number of useful buds obtained per bud of the initial aggregate after three weeks in induction medium. The multiplication rates achieved after the first five subcultures on both accessions are 12.3, 13.4, $14.5,12.2$ and 13.3 as averages of buds per explant per subculture. The two J. curcas accessions still showed similar behavior with regard to the formation of buds aggregates.

The histological sections carried out on the bud aggregates show new buds developing continuously from each leaf axil (Figure 4a). This phenomenon occurred without callogenesis and was conform to a strict axillary budding process. In this case, we could observe the absence of the dominance normally

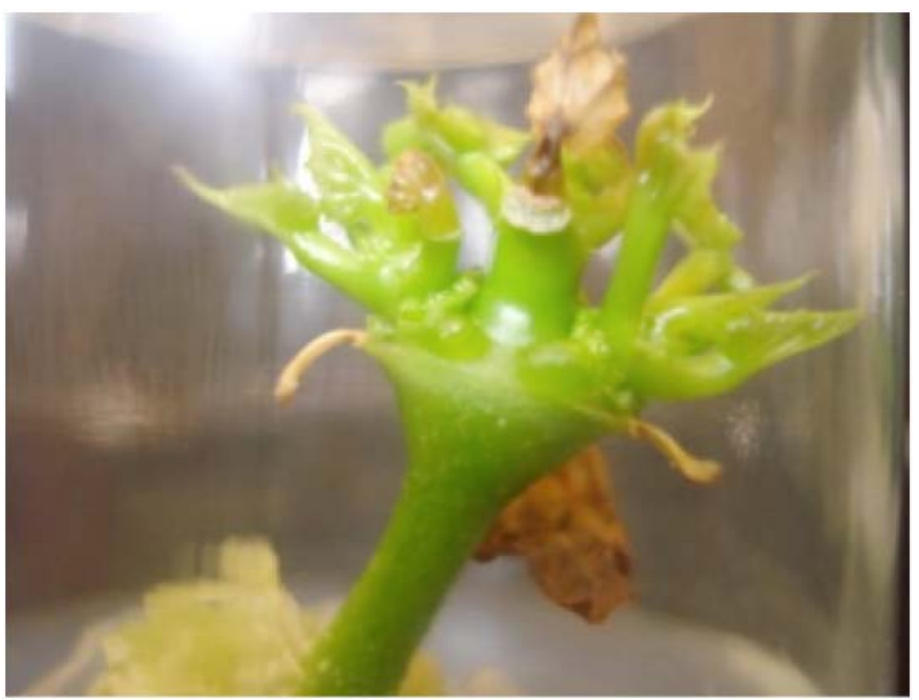

a

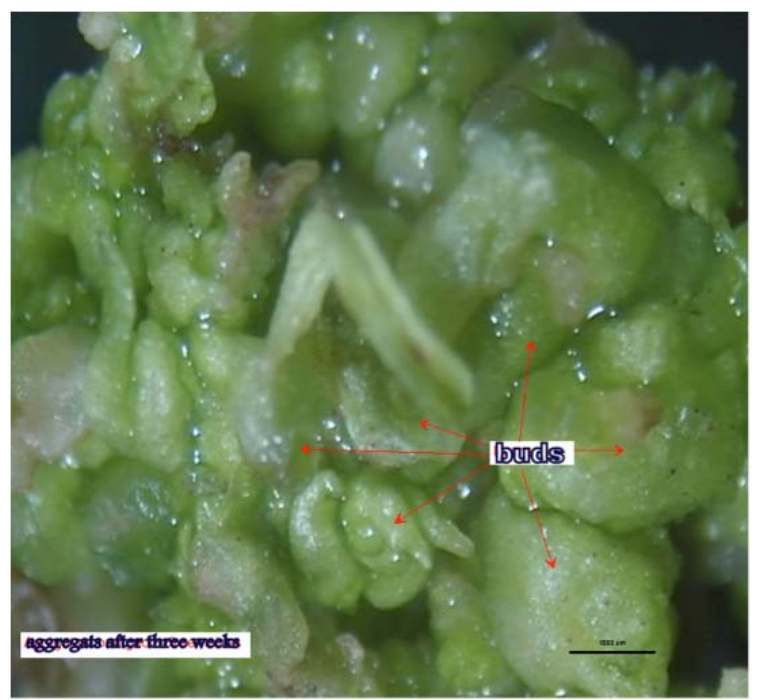

b

Figure 1: Bud aggregate development stages in J. curcas, Cameroon accession. a) Axillary buds on nodal explants after 3 weeks of cultivation on a MS medium supplemented with $8.87 \mu \mathrm{M} B A, 4.92 \mu \mathrm{M}$ IBA, $3 \%$ sucrose and $0.7 \%$ agar b) Bud aggregate after 3 weeks of cultivation on a MS medium supplemented with $6.65 \mu \mathrm{M} \mathrm{BA}, 2.46 \mu \mathrm{M}$ IBA, 25 mg. I $^{-1}$ glutamine, 25 mg..$^{-1}$ citric acid, $12.2 \mathrm{mg} . \mathrm{I}^{-1}$ adenine sulfate and $15 \mathrm{mg} . \mathrm{I}^{-1}$ to $\mathrm{L}$-arginine, $3 \%$ sucrose and $0.7 \%$ agar (bar : $1000 \mu \mathrm{m}$ ). 


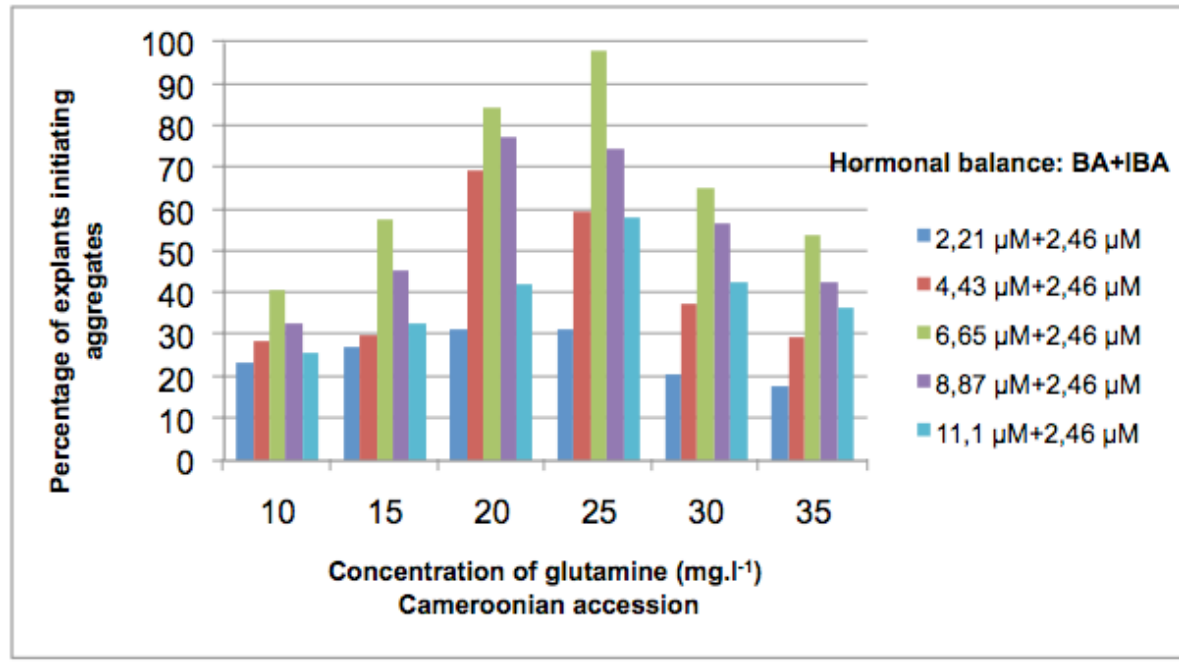

a

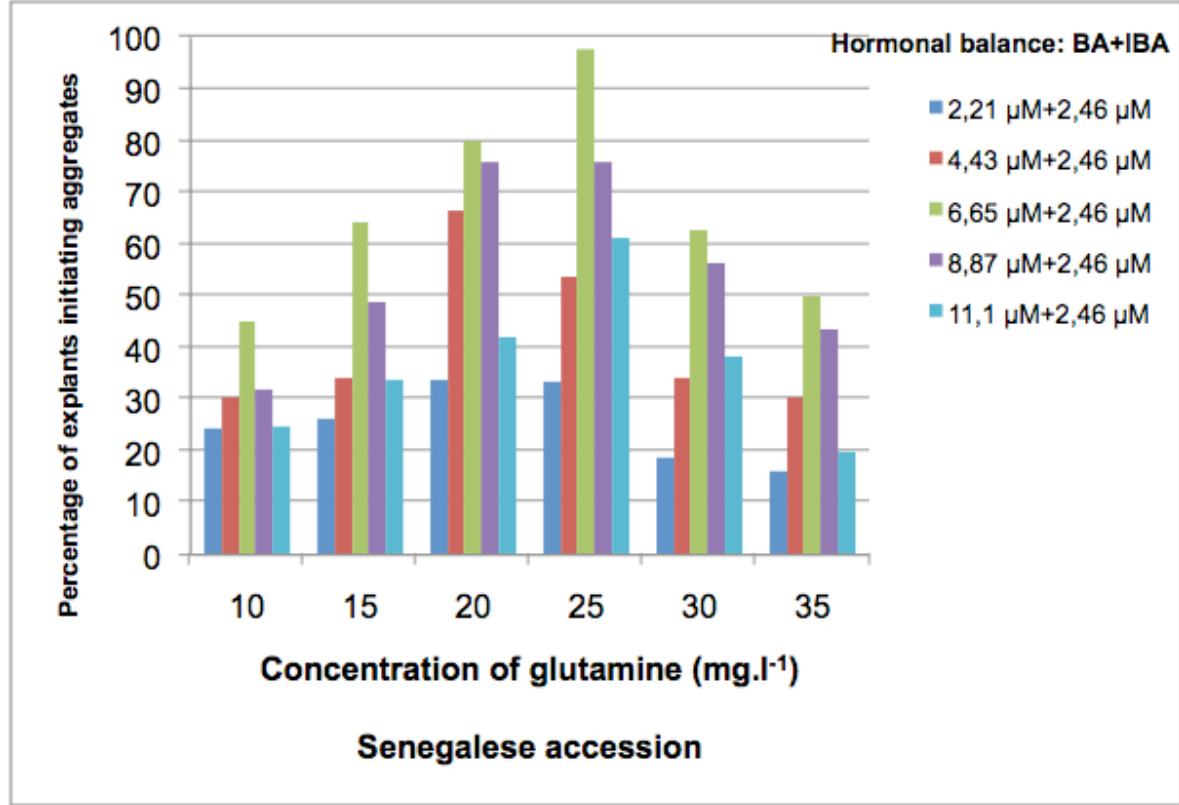

b

Figure 2: Percentage of nodal explants initiating bud aggregates on the Cameroonian (a) and Senegalese (b) accessions. Both accessions were cultivated in induction media supplemented with $25 \mathrm{mg} . \mathrm{I}^{-1}$ citric acid, $12.2 \mathrm{mg} . \mathrm{I}^{-1}$ adenine sulfate, $15 \mathrm{mg} . \mathrm{I}^{-1}$ of $\mathrm{L}$ arginine, $3 \%$ sucrose and $0.7 \%$ agar. Averages were calculated on basis of 3 repetitions of 26 explants each.

exerted by the apical buds of the shoots. Moreover, a direct adventive regeneration took place from the underlying tissues (Figure 4b) simultaneously to axillary budding within the same bud aggregate.

From the 5 and 10 buds forming the aggregate fragments, 3 to 4 became dominant over the others to reach an average size of $1.5 \mathrm{~cm}$. The rest of the aggregate fragment was placed back into the same elongation condition, after collecting the elongated shoots. This operation was necessary to develop all the buds from an aggregate fragment into shoots able to root (Figure 4c).
Roots appear at the base of leafy stems as soon as the 12th day after their transfer to the rooting medium. Results show that the induction medium has an influence on the rooting potential of the stems. Table 1 shows the percentage of rooting obtained on the two accessions of $J$. curcas after four weeks on MS rooting medium containing $2.46 \mu \mathrm{M}$ IBA, $2 \%$ sucrose and $0.7 \%$ agar according to the concentration of $\mathrm{BA}$ and glutamine in the induction medium. There was no significant difference in the percentage of rooting stems for the two accessions of $J$. curcas whatever of the concentration of glutamine in their native medium. However, percentage of rooting varies very significantly 


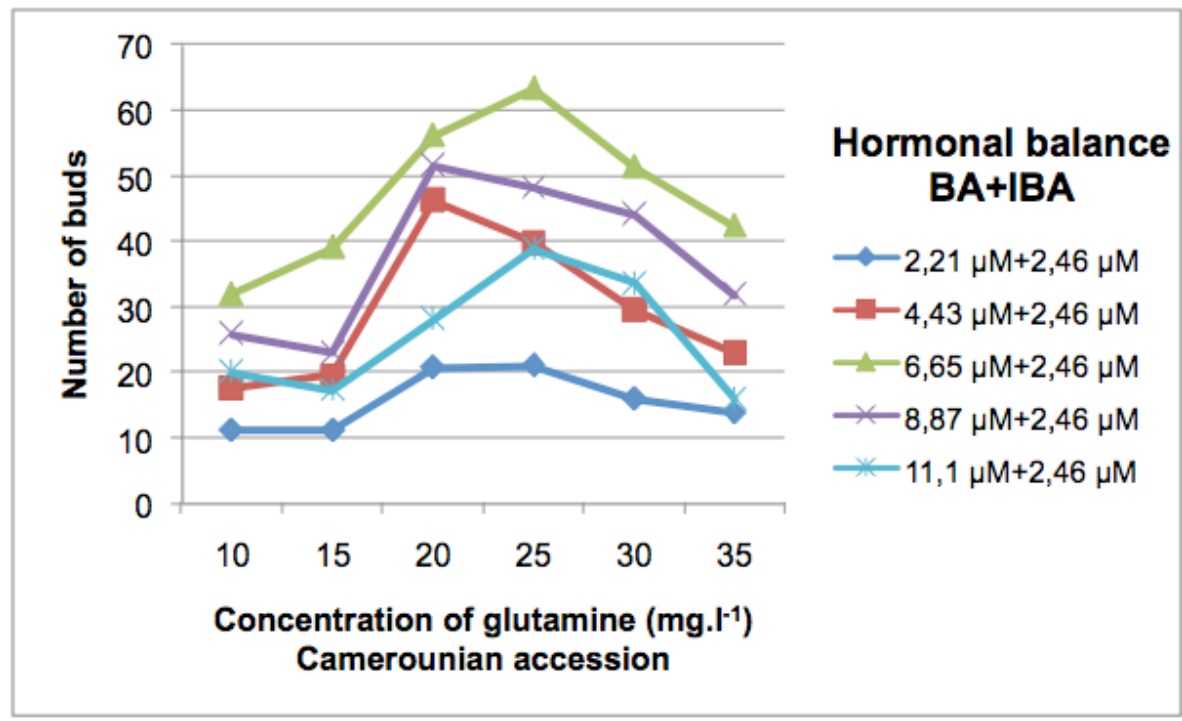

a

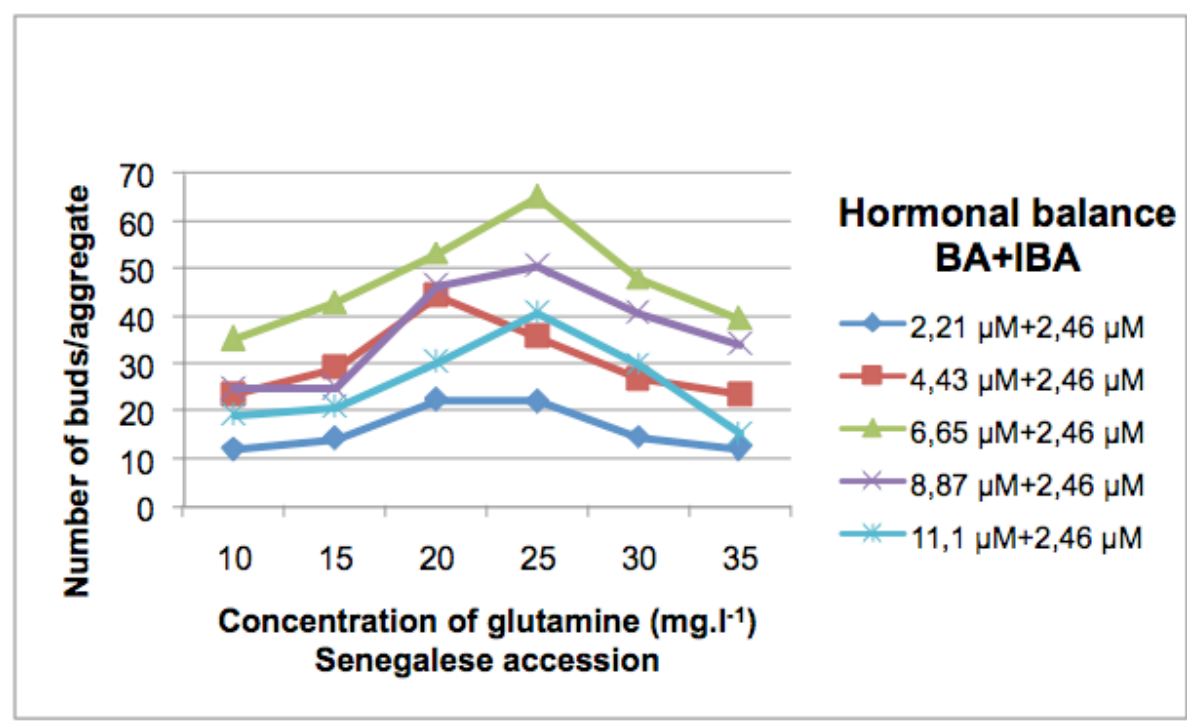

b

Figure 3: Average number of buds obtained from each aggregate on the different induction media according to glutamine concentration in the media. All media were supplemented with $25 \mathrm{mg} . I^{-1}$ citric acid, $12.2 \mathrm{mg} . \mathrm{I}^{-1}$ adenine sulfate, $15 \mathrm{mg} . \mathrm{I}^{-1} \mathrm{~L}$ arginine, $3 \%$ sucrose and $0.7 \%$ agar.

Averages were obtained from 3 replications with 26 explants/assay.

with the concentration of $B A$ in the induction medium and was higher on the stems originating from media containing low concentrations of BA. Optimal values were observed with stems cultured in MS media supplemented with $2.21 \mu \mathrm{M}$ BA with rooting percentages as high as $90.10 \pm 6.23$ and $86.10 \pm 5.02 \%$ respectively for the Cameroonian and Senegalese accessions.

As for the lowest rooting percentages, they were obtained with the induction media containing the highest BA concentration, i.e. 11.1 $\mu \mathrm{M}$ BA, with rooting percentages as low as, respectively, $31.27 \pm 1.60 \%$ and $35.17 \pm 0.49 \%$ for the Cameroon and Senegal accessions. Callus formation at stem basis was also noted during the rooting phase of stems originating from media containing 11.1 or $8.87 \mu \mathrm{M} \mathrm{BA}$. All obtained roots, regardless of the origin of the stems, developed little or no secondary roots.

In the rooting medium, the roots appeared from the 12 th day of growth. After 4 weeks, $96.32 \%$ of the shoots bore an average of $2 \pm 037$ roots; with an average length of $0.7 \pm 0.68 \mathrm{~cm}$. Rooted stems (Figure 5a) were transferred to acclimatization. They lose all roots produced in vitro after about 10 days and initiate new roots. There was no significant difference in the survival rates during acclimatization of rooted stems 


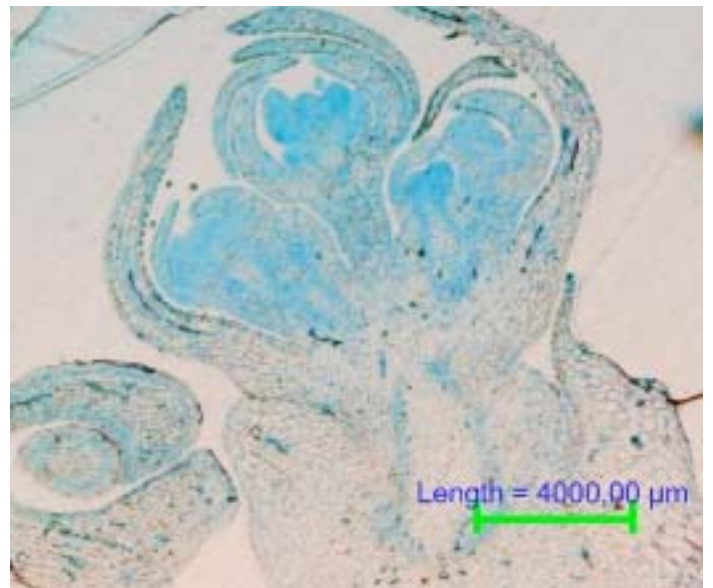

a

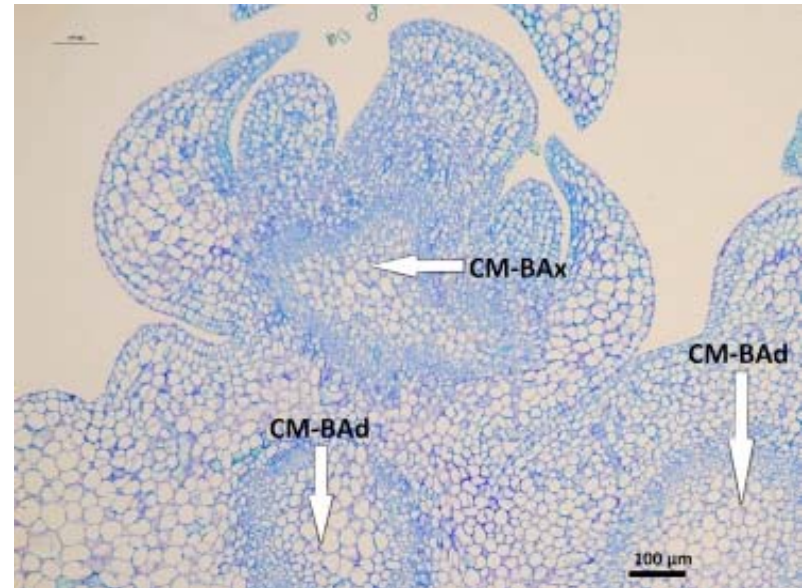

b

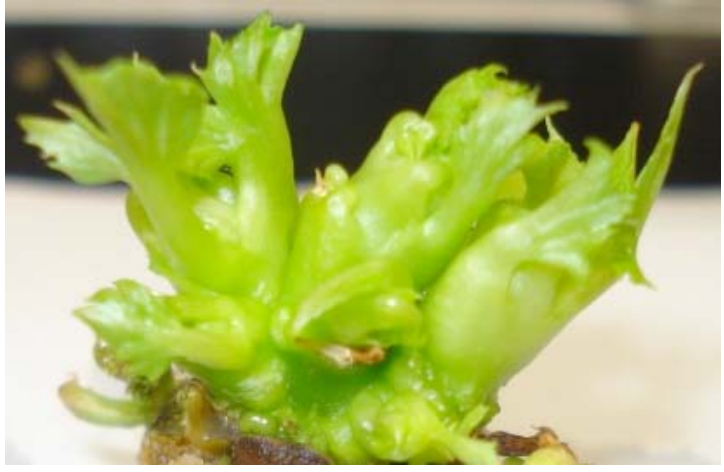

c

Figure 4: In vitro bud cluster induction in J. curcas through axillary and adventitious regeneration for the Cameroonian accession. a) Histological section showing the axillary origin of the buds in the aggregates after 3 weeks of culture on a MS medium containing 6.65 $\mathrm{MM} \mathrm{BA}, 2.46 \mu \mathrm{M}$ IBA, $25 \mathrm{mg} . .^{-1}$ glutamine, $25 \mathrm{mg} . \mathrm{I}^{-1}$ citric acid, $12.2 \mathrm{mg} . \mathrm{I}^{-1}$ adenine sulfate, $15 \mathrm{mg}^{-1} \mathrm{I}^{-}$of L-arginine, $3 \%$ sucrose and $0.7 \%$ agar $\mathbf{b})$ Histological section of a bud aggregate of 3 weeks presenting axillary and adventitious regeneration from underlying tissues. The bud were grown on a MS medium supplemented with $6.65 \mu \mathrm{M} \mathrm{BA}, 2.46 \mu \mathrm{M}$ IBA, 25 mg. $\mathrm{I}^{-1}$ glutamine, $25 \mathrm{mg} . \mathrm{I}^{-1}$ citric acid, $12.2 \mathrm{mg}^{-1}$ adenine sulfate, $15 \mathrm{mg} . \mathrm{I}^{-1} \mathrm{~L}$-arginine $3 \%$ sucrose and $0.7 \%$ agar $(\mathrm{CM}-\mathrm{Bad}$ : meristematic center for adventitious budding of underlying tissues, CM-BAx: meristematic center for axillary budding) c) Fragment of a three weeks old bud aggregate grown on MS elongation medium supplemented with $2.21 \mu \mathrm{M}$ and $5.70 \mu \mathrm{M}$ BA IAA (indole-3-acetic acid), $15 \mathrm{mg} . \mathrm{I}^{-1} \mathrm{~L}$-arginine, $3 \%$ sucrose and $0.7 \%$ agar.

Table 1: Impact of Bud Aggregate Induction Medium on the Average Percentage of Rooting Stems in the Rooting Medium ( $1 / 2$ MS Containing $2.46 \mu \mathrm{M}$ IBA, 2\% Sucrose and $0.7 \%$ Agar) for the Cameroon and Senegalese Accessions of $J$. curcas

\begin{tabular}{|c|c|c|c|c|c|c|c|}
\hline \multirow[b]{2}{*}{$\begin{array}{c}\text { Induction medium } \\
\qquad B A+I B A(\mu M)\end{array}$} & \multirow[b]{2}{*}{ Accession } & \multicolumn{6}{|c|}{ Glutamine concentration in the induction medium $\left(\mathrm{mg} . \mathrm{I}^{-1}\right)$} \\
\hline & & $10\left(\mathrm{mg} . \mathrm{I}^{-1}\right)$ & $15\left(\mathrm{mg} . \mathrm{I}^{-1}\right)$ & $20\left(\mathrm{mg} . \mathrm{I}^{-1}\right)$ & $25\left(\mathrm{mg} \cdot \mathrm{I}^{-1}\right)$ & $30\left(\mathrm{mg} . \mathrm{I}^{-1}\right)$ & $35\left(\mathrm{mg} . .^{-1}\right)$ \\
\hline \multirow{2}{*}{$\begin{array}{c}\mathrm{BA}(11.1)+\mathrm{IBA} \\
(2.46)\end{array}$} & Cam & $36.97 \pm 1.16 a$ & $36.87 \pm 0.67 a$ & $31.27 \pm 1.60 \mathrm{a}$ & $36.71 \pm 1.68 a$ & $35.88 \pm 1.47 a$ & $41.10 \pm 1.43 a$ \\
\hline & Sen & $35.37 \pm 1.11 \mathrm{a}$ & $35.17 \pm 0.49 a$ & $39.21 \pm 1.10 \mathrm{a}$ & $39.11 \pm 1.48 a$ & $35.23 \pm 1.17 \mathrm{a}$ & $39.11 \pm 1.10 \mathrm{a}$ \\
\hline \multirow{2}{*}{$\begin{array}{c}\mathrm{BA}(8.87)+\mathrm{IBA} \\
(2.46)\end{array}$} & Cam & $45.21 \pm 1.90 a$ & $44.09 \pm 1.88 a$ & $52.56 \pm 1.25 b$ & $18.91 \pm 1.71 b$ & $46.89 \pm 1.88 \mathrm{~b}$ & $47.96 \pm 2.15 b$ \\
\hline & Sen & $43.11 \pm 1.30 \mathrm{~b}$ & $43.19 \pm 1.68 b$ & $51.16 \pm 1.05 b$ & $48.01 \pm 1.61 b$ & $46.09 \pm 1.38 b$ & $56.98 \pm 2.11 \mathrm{~b}$ \\
\hline \multirow{2}{*}{$\begin{array}{c}\mathrm{BA}(6.65)+\mathrm{IBA} \\
(2.46)\end{array}$} & Cam & $52.12 \pm 2.22 b c$ & $51.00 \pm 2.31 \mathrm{c}$ & $61.08 \pm 2.43 c$ & $51.07 \pm 2.22 b$ & $51.81 \pm 2.31 b c$ & $79.98 \pm 3.43 c$ \\
\hline & Sen & $59.02 \pm 2.02 c$ & $50.00 \pm 2.71 \mathrm{c}$ & $59.08 \pm 2.03 c$ & $60.07 \pm 2.02 b$ & $49.71 \pm 2.11 b$ & $67.90 \pm 3.41 \mathrm{c}$ \\
\hline \multirow{2}{*}{$\begin{array}{c}\mathrm{BA}(4.43)+\mathrm{IBA} \\
(2.46)\end{array}$} & Cam & $79.11 \pm 4.89 d$ & $78.06 \pm 4.58 d$ & $81.19 \pm 5.46 \mathrm{~d}$ & $71.66 \pm 4.89 \mathrm{c}$ & $71.69 \pm 4.58 \mathrm{c}$ & $78.19 \pm 4.46 \mathrm{~d}$ \\
\hline & Sen & $77.91 \pm 4.09 d$ & $76.16 \pm 4.18 d$ & $79.19 \pm 4.06 d$ & $70.36 \pm 4.19 c$ & $79.69 \pm 4.08 c$ & $77.17 \pm 4.41 \mathrm{~d}$ \\
\hline \multirow{2}{*}{$\begin{array}{c}\mathrm{BA}(2.21)+\mathrm{IBA} \\
(2.46)\end{array}$} & Cam & $90.10 \pm 6.23 \mathrm{e}$ & $86.04 \pm 5.22 \mathrm{e}$ & $89.05 \pm 5.85 \mathrm{e}$ & $78.99 \pm 4.32 d$ & $81.04 \pm 5.22 d$ & $86.15 \pm 5.85 \mathrm{e}$ \\
\hline & Sen & $86.10 \pm 5.02 \mathrm{e}$ & $84.04 \pm 5.12 \mathrm{e}$ & $87.05 \pm 5.05 \mathrm{e}$ & $76.90 \pm 4.12 d$ & $79.04 \pm 5.02 d$ & $84.15 \pm 5.75 \mathrm{e}$ \\
\hline
\end{tabular}

Average percentage \pm SE of rooted shoots after 4 weeks, with 3 replicates (26 shoots / replicate). Values in each column followed by same letters are not significantly different according to Duncan's multiple range test at $\alpha=0.05$. 


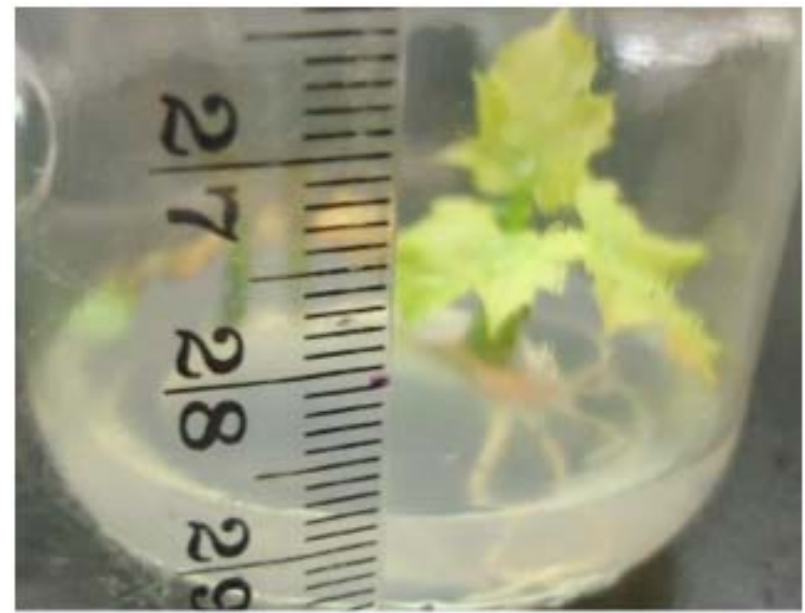

a

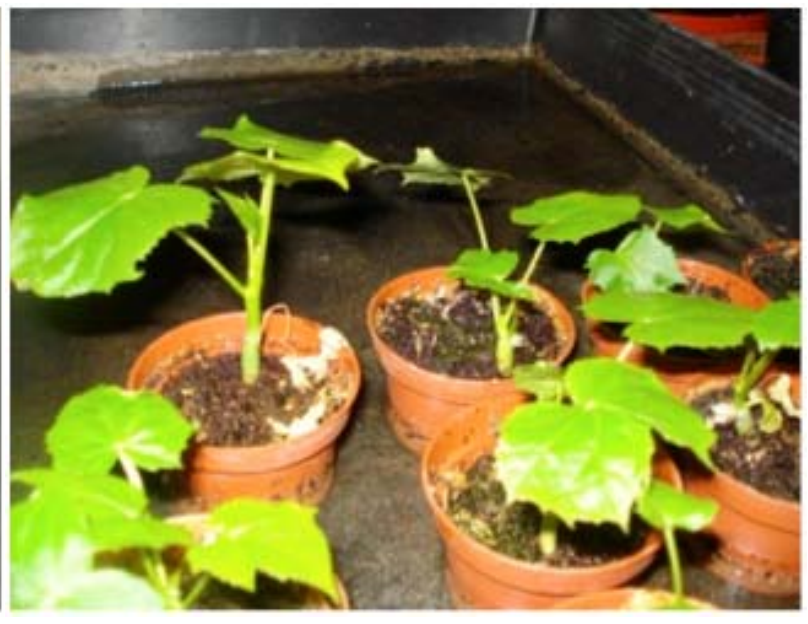

b

Figure 5: Rooting and acclimatization of $J$. curcas vitroplants (Cameroon accession). a) Four week old rooted stem on MS medium containing $2.46 \mu \mathrm{M}$ IBA, $2 \%$ sucrose and $0.7 \%$ agar, b) Acclimated 5 weeks old J. curcas vitro-plants.

whatever their background. The survival rate is of $98 \%$ in acclimatization and obtained vitroplants showed no morphological abnormalities after being transferred to greenhouses (Figure 5b).

\section{DISCUSSION}

The absence of a significant difference between both tested accessions with respect to the induction of bud aggregates could be linked to insufficient genetic variation between them. Similar observations were made with several cultivars of $J$. curcas [8]. The formation of bud aggregates and the variability of induction performances were influenced by the interaction between the phytohormones and the amino acid supplied to the IM medium. The concentration of endogenous cytokinins and their control mechanisms would be the most important elements that could explain these differences. The absence of the apical dominance combined with the direct adventive regeneration from the underlying tissues of the bud, led to the formation of bud aggregates without involving the production of callus. A highly productive protocol applied to several cultivars of Malus domestica Borkh was established from shoot apex, but the buds regeneration included callogenesis [9]. That presents the risks of conformity alterations within the regenerants as it often is the case for adventive regeneration.

The shoot bud differentiation was observed on MS media supplemented with cytokinines. By means of axillary regeneration, we have been able to obtain $30.80 \pm 5.5$ shoots/explant of J.curcas on a MS medium containing $2.30 \mu \mathrm{M}$ kinetine, $0.50 \mu \mathrm{M}$ IBA, $27.8 \mu \mathrm{M}$ of adenine sulfate and $30{\mathrm{~g} . \mathrm{I}^{-1}}^{-1}$ sucrose after 4 to 6 weeks of growth. Nevertheless this medium induced the formation of calluses and thus the risk of somaclonal variation. Similarly, Medza and co. regenerated $40.4 \pm 8.80$ shoots per axillary bud from a nodal explant on MS containing $6.65 \mu \mathrm{M}$ BA and $2.46 \mu \mathrm{M}$ IBA, 33.12 $\mu \mathrm{M}$ of adenine sulfate, $30.53 \mathrm{mg} . \mathrm{I}^{-1}$ glutamine and 30 mg. I $^{-1}$ sucrose, after 4 weeks of growth but without any callus formation [6]. While the response obtained depends on the hormonal balance and of the kind of cytokinin used, it is also linked to the type of explant, as well as their physiological state. Among the cytokinins, $B A$ is the best to stimulate the buds regeneration and proliferation from nodal explants of $J$. curcas [10]. The BA and IBA combination provided the best shoot bud induction of 6.0 shoots per explant. However the authors noticed differences in responses among genotypes which they attributed to endogenous concentration of hormones. Shoot tips of J. curcas were cultured on MS combination of $8.87 \mu \mathrm{M}$ BAP and $2.85 \mu \mathrm{M}$ IAA along with adenine sulfate, glutamine and activated charcoal. The plants produced by the direct organogenesis method exhibit greater genetic stability than those produced via callus-mediated organogenesis [11].

The amino acids added to the growth medium can act in synergy with growth regulators to regenerate entire plants of Cichorium intybus L. by induction of meristematic nodules from wounded leaves. That adventive regeneration method showed a high regeneration potential close to that of bud aggregates. In our trials, the glutamine was shown to be indispensable to the formation of bud aggregates [11]. Glutamine is frequently employed in the culture 
medium as an organic nitrogen source. Many papers have shown that the use of exogenous glutamine can be beneficial for in vitro culture, increasing the regeneration rate and biomass of the explants. As easily accessible source of reduced nitrogen, it is generally more favorable than ammonium, to morphogenesis as reported for Cucumis sativus L. In the course of work done with the in vitro multiplication of Arachis hypogea L. from cotyledon explants, the presence of L-glutamine also improved and maintained high multiplication and growth rates. During transamination, glutamine transfers nitrogen to other carbohydrated substrates (a-keto acids) and the new amino acids immediately contribute to the biosynthesis of proteins $[12,13]$. The glutamine and glutamate byproduct are the primary sources of reduced nitrogen in the cellular metabolism. They contribute to the transamination. where ammonium is incorporated by the action of the glutamine synthetase and glutamate synthase [14] to form aspartate and asparagine. They are the precursors of all other amino acids [15] involved in protein biosynthesis and morphogenesis like buds aggregates process.

Glutamine in combination with inorganic forms of nitrogen has generally been used in vitro. In bromeliads, glutamine was an excellent nitrogen source to improve gain of dry shoot mass of plantlets cultivated in vitro [16]. The glutamine had a strong influence on shoot hormonal contents (cytokinin) and it has a great effect on the promotion of shoot-bud organogenesis from leaf base pineapple explants. Glutamine and glutamate are known to be the main endogenous amino acids involved in plant metabolism, providing nitrogen for the biosynthesis of amino acids, nucleic acids and other $\mathrm{N}$-compounds [17].

Amino acids played a vital role in the induction and development of a maximum number of multiple shoots [12]. Adenine sulfate is a substrate for the synthesis of natural cytokinins [18]; its beneficial effect on the axillary budding from nodal explants is corroborated by the work on the in vitro organogenesis. Its absence in the optimal IM medium caused a reduction in the number of buds formed by aggregate (data not shown). The exogenous supply of adenine is recovered and utilized for ATP (Adenosine Triphosphate) and nucleic acid synthesis during the development of in vitro micropropagation. The enlargement of the nucleotide pool is required for rapid cell proliferation and growth of the tissue [19].

The formation of bud aggregates was also favored by L-arginine that takes part in the synthesis and/or activity of the polyamines which cause hormone-like effects in plants [20]. They stabilize the protoplasms and influence the cell division while at the same time retard the senescence of the tissues. Their polycationic shape leads to connections with nucleic acids and plasmalemma phospholipids and allow for better permeability of the cell membranes [21].

It was shown that the products of L-arginine synthesis increase budding. The combination of these products to glutamine and arginine is a factor enhancing protein accumulation. The development of axillary nodes from explants was also performed on MS medium containing $4.90 \mu \mathrm{M}$ IBA and $13.31 \mu \mathrm{M}$ of BA [22]. Citric acid has been recognized as a very efficient anti-oxidant compound in in vitro culture [23, 24]. It prevents the production of polyphenols which often hinder organogenesis and cause explant necrosis. For in vitro propagation of Acacia plantlets, citric acid was the most effective in supporting axillary shoot proliferation and preventing browning of the medium [25].

The detailed study on histological events of in vitro growth and morphogenesis of $J$. curcas shows that the process of shoot morphogenesis happens through adventitious shoot morphogenesis and axillary development. These two types of plant regeneration were observed - one type of shoot regeneration was via organogenesis from underlying tissues - and the second type was through multiplication of the preexisting meristems. It is, however, interesting to note that under similar experimental conditions the process of organogenesis varied from explant to explant. The authors attributed the difference in regeneration response to pre-disposed genetic conditions [26].

During the buds to shoot elongation stage, Larginine prepares the shoots for rooting. A few buds were dominant over other buds of the same aggregate fragment and inhibited their growth. Once the first shoots were harvested from the fragment, the resting buds immediately started to grow into shoots as observed in various woody plants [27]. Consequently, such apical dominance leads to asynchronous development of buds differing in their physiological stage at the moment of their transfer to elongation medium. The addition of a hormone-free MS nutrient solution as a double phase on the gelled elongation medium one week preceding the transfer to rooting media, contributed to the dilution of endogenous cytokinins. This dilution liberates the buds from the negative effects of cytokinins on root formation. 
The highest rooting rate in J. curcas was $19.43 \%$ on $1 / 2 \mathrm{MS}$ and $15 \mu \mathrm{M}$ IBA, $11.4 \mu \mathrm{M}$ IAA and $5.5 \mu \mathrm{M}$ NAA (Naphthalene Acetic Acid) as auxin cocktail. The high rate of rhizogenesis is therefore linked to the presence of IBA in the medium [28]. In our trials, rooting of pre-elongated shoots was favored by a pretreatment in darkness at the beginning of rooting. This pretreatment of the shoots improved roots induction and initiation in several other woody species [27]. Darkness influences the endogenous metabolism of the shoots during the successive phases of the rhizogenesis with, notably, a rapid drop in the activity of endogenous peroxidase and phenolic compounds during the first five days of culture [29]. On the other hand, the use of $1 / 2 \mathrm{MS}$ medium increases the $\mathrm{C} / \mathrm{N}$ ratio by reducing the supply of nitrogen which is favorable to root formation. The rooting percentage variations could also be related to the mechanisms of control, the level of endogenous growth regulators and their metabolism. The high concentrations of cytokinins inhibit root formation, which would explain the low rooting rates obtained on stems originating from media with high levels of BA. The absence of secondary roots may be related to stress in the stem formation medium. The amount and the quality of secondary roots determine the survival rate during acclimatization. However, despite the absence of such roots, survival rates have remained high in acclimatization [10].

\section{CONCLUSION}

In the present study, it has been clearly established that the $J$. curcas plantlets were regenerated in vitro by direct induction of buds aggregates. Replanting the buds into an optimized MI medium led in 13 weeks to obtain a total average of $65.13 \pm 1.12$ plantlets per bud originating from the development of nodal explant. The acclimatized plants do not present any visual defects and did not show any malformation. The performance gain from this micropropagation protocol, with a multiplier of 13 is double those obtained by other authors [10]. Its use would be more economically viable for the production of planting material. However, the conformity of clonal plantlets has to be confirmed after checking their behavior during the all plant growth cycle and before any application of the technique at a large scale.

\section{ACKNOWLEDGEMENTS}

We thank the Institutional Support Program in Human Resources Development (PAI-DRH) program of the Ministry of Economy, Budget, Public Accounts, the Civil Service and State Reform in the Republic of Gabon; the National Institute for Higher of Agronomy and Biotechnology, University of Science and Technology of Masuku (USTM-INSAB), Gabon, and the University of Liège Gembloux Agro-Bio Tech.

\section{REFERENCES}

[1] Leela T, Naresh B, Srikanth Reddy M, Madhusudhan NC, Cherku PD. Morphological, physico-chemical and micropropagation studies in Jatropha curcas L. and RAPD analysis of the regenerants. Appl Energy 2011; 88(6): 20719.

http://dx.doi.org/10.1016/j.apenergy.2010.12.080

[2] Openshaw K. A review of Jatropha curcas: an oil plant of unfulfilled promise. Biomass Bioenergy 2000; 19: 1-15. http://dx.doi.org/10.1016/S0961-9534(00)00019-2

[3] Jha T, Mukherjee P, Datta M. Somatic embryogenesis in Jatropha curcas Linn., an important biofuel plant. Plant Biotechnol Reports 2007; 1(3): 135-40. http://dx.doi.org/10.1007/s11816-007-0027-2

[4] Nyamai DO, Omuodo LO. Jatropha curcas: the untapped potential in eastern and central Africa. manual Pau, editor. Nairobi, Kenya 49 p: Vanilla-Jatropha Development Foundation 2007.

[5] Murashige T, Skoog F. A Revised Medium for Rapid Growth and Bio Assays with Tobacco Tissue Cultures. Physiologia Plantarum 1962; 15(3): 473-97. http://dx.doi.org/10.1111/j.1399-3054.1962.tb08052.x

[6] Medza Mve SD, Mergeai G, Jean-Pierre B, André T. Amélioration du taux de multiplication in vitro de Jatropha curcas L. Tropicultura 2010; 28(4): 200-4.

[7] Ruzin SE. Plant microtechnique and microscopy. New York, USA, 322 p: Oxford University Press 1999; p. 322.

[8] Sharma S, Sudheer Pamidimarri DVN, Vijay Anand KG, Reddy MP. Assessment of genetic stability in micropropagules of Jatropha curcas genotypes by RAPD and AFLP analysis. Industrial Crops Products 2011; 34(1): 10039.

http://dx.doi.org/10.1016/j.indcrop.2011.03.008

[9] Caboni E, Lauri $\mathrm{P}$, D'Angeli S. In vitro plant regeneration from callus of shoot apices in apple shoot culture. Plant Cell Reports 2000; 19(8): 755-60. http://dx.doi.org/10.1007/s002999900189

[10] Datta MM, Mukherjee P, Ghosh B, Jha TB. In vitro clonal propagation of biodiesel plant (Jatropha curcas L.). Curr Sci 2007; 93(10): 1438-42.

[11] Piéron S, Belaizi $M$, Boxus $P$. Nodule culture, a possible morphogenetic pathway in Cichorium intybus $\mathrm{L}$. propagation. Scientia Horticulturae 1993; 53(1-2): 1-11. http://dx.doi.org/10.1016/0304-4238(93)90132-A

[12] Vasanth K, Lakshmiprabha A, Jayabalan N. Amino acids enhancing plant regeneration from cotyledon and embryonal axis of peanut (Arachis hypogaea L.). Indian J Crop Sci 2006; 1(1-2): 79-83.

[13] Vasudevan A, Selvaraj N, Ganapathi A, Kasthurirengan S, Ramesh Anbazhagan V, Manickavasagam M. Glutamine: a suitable nitrogen source for enhanced shoot multiplication in Cucumis sativus L. Biologia Plantarum 2004; 48(1): 125-8. http://dx.doi.org/10.1023/B:BIOP.0000024288.82679.50

[14] Miflin BJ, Habash DZ. The role of glutamine synthetase and glutamate dehydrogenase in nitrogen assimilation and possibilities for improvement in the nitrogen utilization of crops. J Exp Bot 2002; 53: 979-87. http://dx.doi.org/10.1093/jexbot/53.370.979

[15] Peoples MB, Gifford RM. Long distance transport of carbon and nitrogen from sources to sinks in higher plants. In: 
Dennis D, Turpin DH, editors. Plant Physiology, Biochemistry and Molecular Biology. New York, USA1993; pp. 434-47.

[16] Mercier H, Kerbauy GB. Endogenous IAA and cytokinin levels in bromeliad shoots as influenced by glutamine and ammonium nitrate treatments. Rev Bras Fisiol Veg 1998; 10: 225-8.

[17] Coruzzi G, Last R. Amino acids. In: Buchanan B, Groissem W, Jones R, Eds. Biochemistry and Biology of Plants. USA: American Society of Plant Physiologists 2000; pp. 358-410.

[18] Staden J, Crouch NR. Benzyladenine and derivatives-their significance and interconversion in plants. Plant Growth Regulation 1996; 19: 153-75. http://dx.doi.org/10.1007/BF00024582

[19] Ashihara H, Stasolla C, Loukanina N, Thorpe TA. Purine metabolism during white spruce somatic embryo development: salvage of adenine, adenosine, and ionosine. Plant Sci 2001; 160: 647-57. http://dx.doi.org/10.1016/S0168-9452(00)00441-6

[20] Kakkar RK, Sawhney VK. Polyamine research in plants-a changing perspective. Physiol Plant 2002; 116: 281-92. http://dx.doi.org/10.1034/j.1399-3054.2002.1160302.x

[21] Galston AW, Kaur-Sawhney R. Polyamines as endogenous growth regulators. In: Davies PJ, editor. Plant hormones and their role in plant growth and development. Dordrecht, Netherlands: Martinus Nijhoff 1987; pp. 280-95. http://dx.doi.org/10.1007/978-94-009-3585-3 15

[22] Morcillo F, Aberlenc-Bertossi F, Trouslot P, Hamon S, Duval $Y$. Characterization of $2 S$ and $7 S$ storage proteins in embryos of oil palm. Plant Sci 1997; 122(2): 141-51. http://dx.doi.org/10.1016/S0168-9452(96)04555-4
[23] Brassard N, Richer C, Toussignant D, Rioux JA. Multiplication végétative de l'Acer saccharum: contribution à la micropropagation. Can J Forest Res 2003; 4: 682-90. http://dx.doi.org/10.1139/x02-192

[24] Shrivastava S, Banerjee M. Algal filtrate: A low cost substitute to synthetic growth regulators for direct organogenesis of embryo culture in Jatropha curcas (Ratanjyot). Acta Physiologiae Plantarum 2009; 31(6): 120512. http://dx.doi.org/10.1007/s11738-009-0355-7

[25] Vengadesan G, Ganapathi A, Amutha S, Selvaraj N. In vitro propagation of Acacia species: a review. Plant Sci 2002; 163: 663-71. http://dx.doi.org/10.1016/S0168-9452(02)00144-9

[26] Mukherjee $\mathrm{P}$, Varshney A, Johnson T, Jha T. Jatropha curcas: a review on biotechnological status and challenges. Plant Biotechnol Reports 2011; 5(3): 197-15. http://dx.doi.org/10.1007/s11816-011-0175-2

[27] Druart P. Contribution to the development of in vitro massproduction production techniques of woody species that can be used in fruit growing. Gembloux, Belgique: PhD Thesis, Faculté d'Agronomie de Gembloux 1987.

[28] Kumar D, Singh S, Sharma R, Kumar V, Chandra H, Malhotra K. Above-ground morphological predictors of rooting success in rooted cuttings of Jatropha curcas L. Biomass Bioenergy 2011; 35(9): 3891-5. http://dx.doi.org/10.1016/j.biombioe.2011.06.019

[29] Druart P, Kevers C, Boxus P, Gaspar T. In vitro promotion of root formation by apple leaf buds through darkness effect on endogenous phenols and peroxidases. Zeitschr Pflanzenphysiol 1982; 108: 429-36.

(c) 2013 Medza Mve et al.; Licensee Lifescience Global.

This is an open access article licensed under the terms of the Creative Commons Attribution Non-Commercial License (http://creativecommons.org/licenses/by-nc/3.0/) which permits unrestricted, non-commercial use, distribution and reproduction in any medium, provided the work is properly cited. 